\title{
Realitization and Testing of Mini Extruder for Biomaterial Filament in Biomedical Application
}

\author{
Yudan Whulanzaa ${ }^{\mathrm{a}}$, Joko Setiawan ${ }^{\mathrm{b}}$ \\ a,b Department of Mechanical Engineering \\ Engineering Faculty \\ University of Indonesia \\ Kampus Baru UI, Depok, West Java, 16424 \\ Phone: 021-7270032, Fax: 021-7270033. \\ Email: yudan@eng.ui.ac.id
}

\begin{abstract}
The use of biomaterials in tissue engineering technique requires an engineered scaffold that allow the cells to be growth. Therefore, a specific biomaterial is required to provide a supportive environment for the seeding cell. This study focused on the design and realization of mini-extruder to produce a biocompatible filament material. Later, the filament is applied in a fused deposition modelling to realize biocompatible scaffold. The extruder uses a single screw extruder of $25 \mathrm{~mm}$ diameter with compression ratio of 2 . Moreover, the extruder has an effective length of $305 \mathrm{~mm}$ with a screw length ratio of the feed zone and metering zone by $20 \%$ and $40 \%$. A forming die used has a diameter of $1.7 \mathrm{~mm}$. At the end of the realization step, the device was tested to produce the filament with various parameters which are screw rotational speed, winding speed, temperature and torque. Characterization of the produced filaments were done by measuring the diameter of filaments using the material of polycaprolactone (PCL). The filament results have a range of 0.05-1.48mm in diameter during the testing process.
\end{abstract}

Keywords: Mini extruder; Biomaterial; Tissue Engineering; Scaffold; Fused Deposition Modeling

\section{INTRODUCTION}

Based on the report of American Liver Foundation, 25 million Americans suffer from gall bladder and liver disease. Currently, the medical costs caused by loss of function of tissue such as liver, has exceeded US \$ 39 billion. The demand for liver transplant far exceeds the available supply. Every year, 27,000 people die from chronic liver disorders and only 3,000 people received a liver transplant as reported by Barrere et al [1]. Therefore, tissue engineering is believed to be one approach as regenerative medicine. Briefly, tissue engineering techniques uses biomaterials as implants (sutures, bone plates, joint replacement) to replace or restore the original function of tissue / organ $[2,3]$.

The use of biomaterials as an engineered scaffold field requires at least two properties that is biocompatible and biodegradable. A biocompatible material does not produce adverse response when implanted in the human body [4]. Biodegradable material enables an enzyme or simply because of water content in the body to make the material shrinking and eventually disappear [5].

This research focuses the design and realization of mini extruder and the characterization of resulted filaments. Extrusion process transforms granulate polymer material into a filament in fuse process. Additionally, a specific environment is accommodated to meet the standard of medical device production.

\section{Methodology}

Biomaterials are material that is capable of interacting with biological systems. The existence of these interactions requires materials to be biocompatible. The type of biomaterial that is used in this research is polycaprolactone (Aldrich, Singapore) with 
formula of $(\mathrm{C} 6 \mathrm{H} 10 \mathrm{O} 2) \mathrm{n}$. The melting point and density are known as $60^{\circ} \mathrm{C}$ and 1.145 $\mathrm{g} / \mathrm{cm} 3$, respectively.

\subsection{Mini Extruder Design}

Mini extruder is designed to process the PCL pellet material with a diameter of $4 \mathrm{~mm}$. Designing mini extruder flow rate based on the needs of a relatively small laboratory scale. Based on the needs of the flow rate, it can be determined the dimensions and specifications of screw, barrel, die, heater and the main drive.

Extrusion is a process that combines several operations including mixing, melting, shearing, shaping and forming. Extruder are classified according to the method of operation (with or without heat) and construction (single or twin screw). However, principles are similar on all types where raw materials are inserted into the barrel delivered by the screw. The barrel screw geometry is dependent to volume which compensates an increasing resistance to displacement of the polymer. During the process, polymer fills the space between the barrel and the screw. Briefly, extruder consists of hopper, barrel, screw, screw head, die and heater as shown in Figure 2.1a.
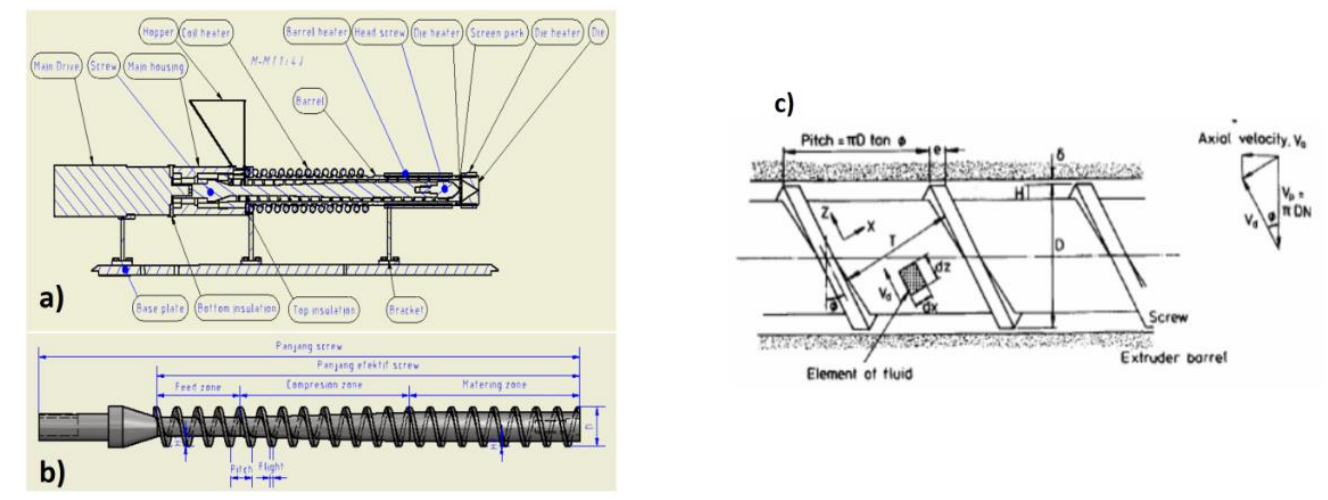

Figure 2.1 a) Major parts of extruder; b) three zones in the extruder and c) parameter of the screw

Screw is the main component that serves the melting of polymer in the die. Screw extruder is divided into three zones, namely a feed zone, compression and mattering zone as shown in Figure 2.1b. Feed zone flows the material from hoper part into screw channel. This zone also provides preheating for the fed granulate polymer. In the compression zone, the granulate polymer are completely melted and packed. Then in the metering zone, a homogeneous molten polymer is formed followed by an increasing pressure. Thereby, this zone pushes the polymer out of the extruder through the die [6].

The determination of screw dimension refers to the standard design parameters from National Institute Industrial Research in Plastic extrusion, moulding and mould design. The parameters are addressed in Table 1 based on the flowrate design.

Table 2.1 Parameter screw

(National Institute Industrial Research, Plastic Extrusion, Moulding and Mould Design)

\begin{tabular}{cccc}
\hline & Parameter & Notation & Standard \\
\hline \multirow{2}{*}{$L$} & Effective length & L2 & $20-30$ \\
\cline { 2 - 4 } $\bar{D}$ & Feed zone length & L3 & $4-8$ \\
\cline { 2 - 4 } & Matering zone length & L5 & $6-15$ \\
\hline & Compression ratio & CR & $2-4$ \\
\hline Feed channel depth & Y2 & $0.1-0.2 \mathrm{D}$ \\
\hline Flight width & W & $0.1 \mathrm{D}$ \\
\hline Helix angle & - & $17.66^{\circ}$ \\
\hline
\end{tabular}

The equation that is applied to calculate output flow of extruder uses basic assumptions of constant viscosity of polymer and isothermal conditions in all parts of the screw. Moreover, the output flow is also influenced by three main components: drag flow, 
pressure flow and leakage [7]. Figure 1c shows the screw geometry where $D$ is the diameter of the screw, $\mathrm{H}$ is the depth of the slot. $\mathrm{P}$ is the pitch or spacing between screw flight, $\delta$ is a clearance between the screw and barrel and $T$ is the width of slot. Drag flow is the flow in the slot screw. Relative speed between the screw and barrel is $(\mathrm{Vd})$. The rate of flow $(\mathrm{Qd})$ can be calculated as:

$$
Q_{d}=\frac{1}{2} T H V_{d}
$$

Based on geometrical design and rotational speed of screw $(\mathrm{N})$, it can be calculated that:

$$
V_{d}=\pi D N \cos \phi
$$

The distance between slot (pitch) is calculated as:

$$
P=\pi D \tan \phi
$$

The width $(\mathrm{T})$ correlates with distance of pitch $(\mathrm{P})$ and width of flight as

$$
\begin{aligned}
& T=(P-e) \cos \phi \approx P \cos \\
& T \approx \pi D \tan \phi \cos \\
& T \approx \pi D \sin \phi
\end{aligned}
$$

Hence, it can be calculated as:

$$
Q_{d}=\frac{1}{2} \pi^{2} D^{2} N H \sin \phi \cos \phi
$$

Shear rate at matering zone is obtained by ratio of $V_{d} / H$.

Pressure flow as flow between flights (back pressure) is calculated as:

$$
Q_{p}=-\frac{T H^{3}}{12 \eta_{a}}\left[\frac{d P}{d z}\right]
$$

Where $\eta_{\mathrm{a}}$ is Newtonian viscosity of polymer.

The pressure distribution can be linearly estimated as:

Where $\eta_{a}$ is the length of matering zone.

$$
\frac{d P}{d z}=\frac{d P}{d l} \frac{d l}{d z}=\frac{d p}{d l} \sin \phi=\frac{P}{l} \sin \phi
$$

By substituting equation 4, we obtain:

$$
Q_{p}=\frac{\pi D H^{3} \sin ^{2} \phi}{12 \eta_{a}} \cdot \frac{P}{l}
$$

Leakage flow occurs in the top flights of as a result of back pressure. It can be calculated as:

$$
Q_{L} \approx-\frac{\pi^{2} D^{2} \delta^{3} \tan ^{2} \phi}{12 \eta_{a} e} \cdot \frac{P}{l}
$$

Hence, the total output is obtained by combining equations from drag flow, back pressure and leakage as follows:

$$
Q=\frac{1}{2} \pi^{2} D^{2} N H \sin \phi \cos \phi-\frac{\pi D H^{3} \sin ^{2} \phi}{12 \eta_{a}} \cdot \frac{P}{l}-\frac{\pi^{2} D^{2} \delta^{3} \tan ^{2} \phi}{12 \eta_{a} e} \cdot \frac{P}{l}
$$

\section{Results and Discussion}

\subsection{Realization of Extruder}

Figures 3.1 shows the solid modeling of mini extruder using Autodesk Inventor 2013 software student version. The total dimension of the extruder (length - width - height) is $480 \mathrm{~mm} \times 100 \mathrm{~mm} \times 205 \mathrm{~mm}$. Figure 3.2 shows the realization of mini-extruder as designed. The motor as screw driver is controlled using Phidgets card and displayed in the personal computer. On the other hand, three heaters were controlled using digital thermostat to give a maximum temperature of $300^{\circ} \mathrm{C}$. Table 3 shows the specification of extruder:
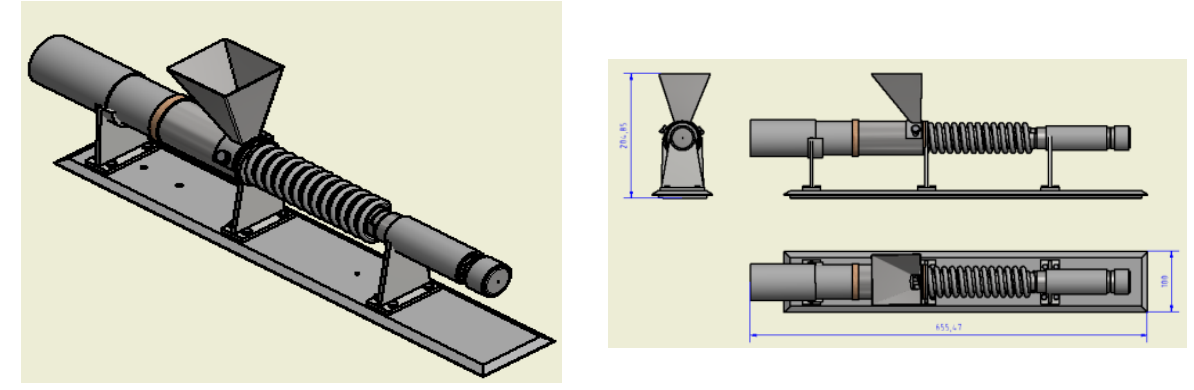

Figure 3.1 Solid modelling of mini extruder

JEMMME | Journal of Energy, Mechanical, Material, and Manufacturing Engineering 


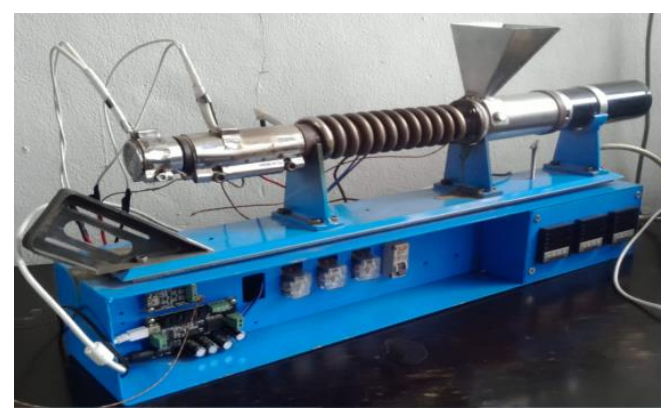

Figure 3.2 Realization of mini extruder

Table 3.1 Extruder specification

\begin{tabular}{clcl}
\hline No & \multicolumn{1}{c}{ Part Name } & $\begin{array}{c}\text { Design } \\
\text { Selection }\end{array}$ & Unit \\
& Screw & VCN 150 & \\
1 & Material & 25 & $\mathrm{~mm}$ \\
2 & Diameter & 390 & $\mathrm{~mm}$ \\
3 & Total length & 305 & $\mathrm{~mm}$ \\
4 & Effective length & 60 & $\mathrm{~mm}$ \\
5 & Feed section length & 122,90 & $\mathrm{~mm}$ \\
6 & Transition zone length & 122,10 & $\mathrm{~mm}$ \\
7 & Matering zone length & 2 & \\
8 & Compression ratio & 4,98 & $\mathrm{~mm}$ \\
9 & Slot thickness & 17,74 & $\mathrm{~mm}$ \\
10 & Pitch slot & 2,5 & $\mathrm{~mm}$ \\
11 & Flight thickness & 0,1 & $\mathrm{~mm}$ \\
12 & Distance between screw and barrel & 17,66 & $\mathrm{Deg}$ \\
13 & Flight angle & $\mathrm{JIS3445}$ & \\
\hline & Barrel & $25 \times 35$ & $\mathrm{~mm}$ \\
1 & Material & 416 & $\mathrm{~kg} / \mathrm{mm}{ }^{2}$ \\
2 & Diameter & & \\
3 & Maximum Pressure & 53 & $\mathrm{RPM}$ \\
\hline & Motor DC & 46 & $\mathrm{Kg}-\mathrm{cm}$ \\
1 & Rotational speed & 51 & \\
2 & Gear reduction & & \\
3 & Maximum Torsion & $220 \mathrm{~V} ; 1200 \mathrm{~W}$ & \\
\hline & Heater & $220 \mathrm{~V} ; 200 \mathrm{~W}$ & \\
1 & Coil heater & $220 \mathrm{~V} ; 100 \mathrm{~W}$ & \\
3 & Band heater 1 (barrel) & & \\
\hline
\end{tabular}

\subsection{Results of Extrusion}

Characterization of Filament's Diameter to Rotational Screw Speed

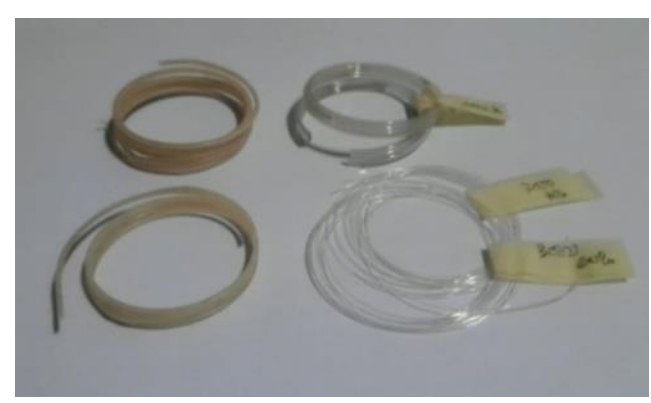

Figure 3.3 Filament produced from the mini extruder 
Figure 3.3 shows the filaments produced from extrusion of polycaprolactone and polypropylene material (darker colour). The diameter of filament is mainly driven from screw rotation speed, winding speed, temperature and torque. Figure 3.4 shows the diameter of filament that resulted from two main parameters which are rotational screw speed and winding speed. Figure 3.5 shows that the filament's diameter tends to increase with increasing of rotational speed screw. It can be described by equation (5), where $\mathrm{N}$ as a screw speed positively affects the volumetric flow of filament.

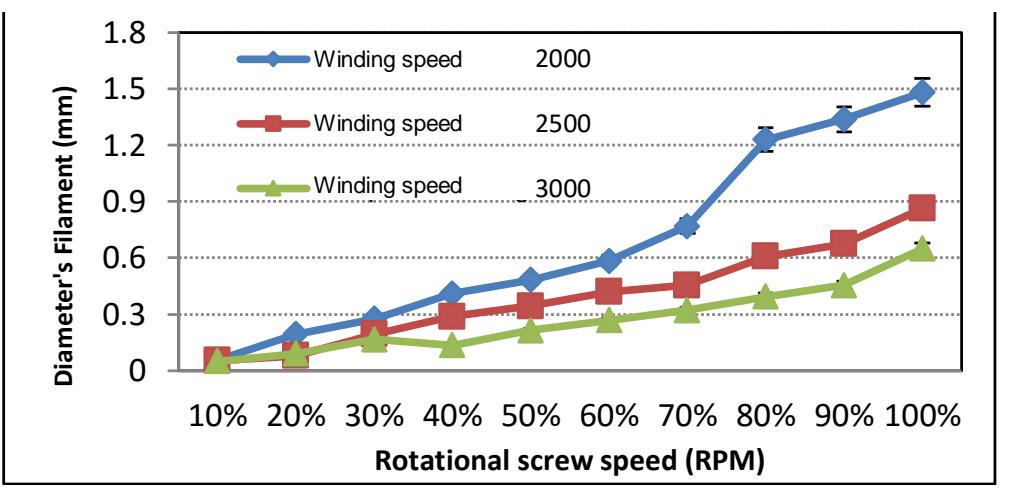

Figure 3.4 The dependency of filament's diameter to the rotational speed screw

The result shows that smallest filament diameter $0.05 \mathrm{~mm}$ is produced by the speed screw at $10 \%$ and filament winding of 3000 RPM. On the other hand, the largest diameter $1.48 \mathrm{~mm}$ is produced by speed screw $100 \%$ and filament winding of 2000 RPM. Statistical analysis shows that the variation of winding speed has a significant different.

\subsubsection{Characterization of Filament's Diameter to Winding Speed.}

Figure 3.5 shows the result of filaments diameter with various speed winding at a constant screw speed. It can be seen that the diameter tends to decrease with the increasing of winding speed. However, figure 3.7 also shows that the decreasing of diameter is insignificant after the winding speed above 4000 RPM. The smallest diameter of $0.28 \mathrm{~mm}$ is achieved at winding speed of 5000 RPM.

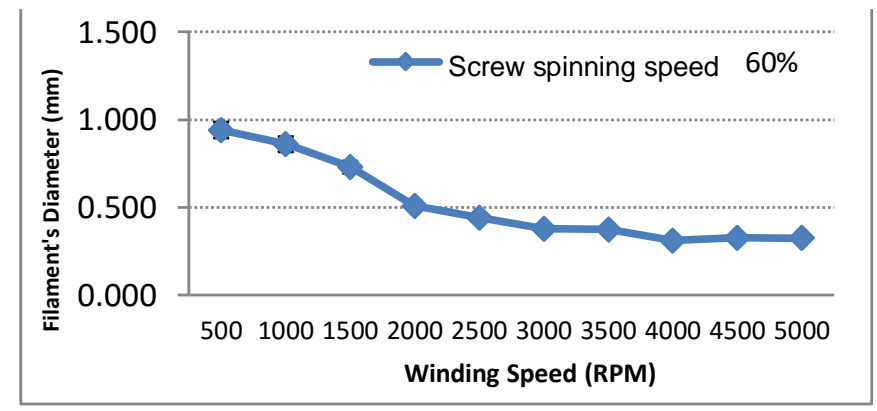

Figure 3.5 The dependency of filament's diameter to winding speed

\subsubsection{Characterization of Filament's Diameter to Heating Temperature.}

As explained in design section, the extrusion is divided into three zones which are: feed; compression and matering zone. These three zones are equipped with independent heater in different locations which are coil heater; barrel and die. Therefore, the temperatures are also set for those three heaters. The data in previous section is produced at heater setting of $180^{\circ} \mathrm{C}-160^{\circ} \mathrm{C}-80^{\circ} \mathrm{C}$. Figure 3.6 shows the variation of filament's diameter in three heating temperature sets.

Figure 3.6 shows that the filament's diameter tends to increase with the increasing temperature of extrusion process. It can be indicated that the viscosity plays important role during the solidification phase in the tip of the mold. As the increasing temperature, the shear rate between polymer particles is reduced. Thus, it extrudes higher amount of 
polymers at the same speed screw. This amount compensates in a bulkier solidified polymer.

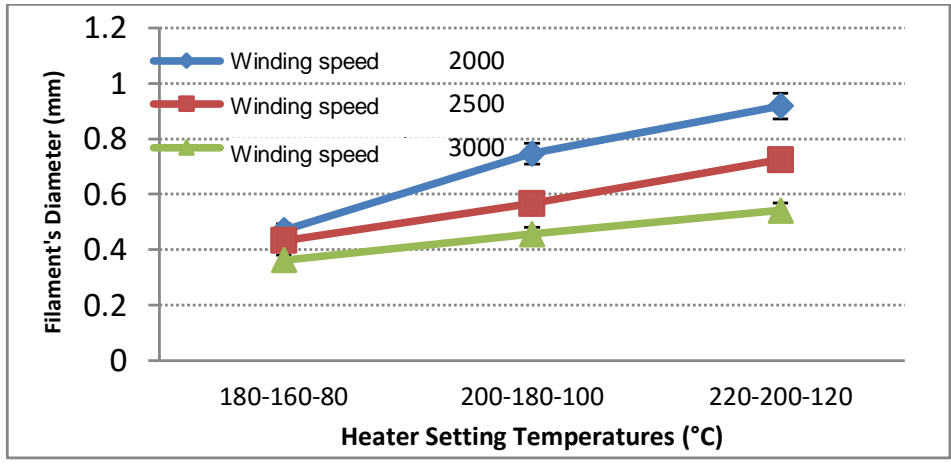

Figure 3.6 The dependency of filament's diameter to heating temperature

The $p$-value statistical analysis shows that the difference is significant with temperature setting. The highest diameter of filament is $0.92 \mathrm{~mm}$ at temperatures setting of $220-200-120^{\circ} \mathrm{C}$. On the other hand, the smallest diameter of filament is $0.43 \mathrm{~mm}$ at temperature setting of $180-160-80^{\circ} \mathrm{C}$.

\section{Conclusion}

Realization of mini extruder with quite small capacity production of biomaterial filament is completed successfully. The characterization of filament's dimension shows that screw speed, winding speed and temperature setting affect significantly. The dimensions that can be obtained are ranging from $0.05-1.48 \mathrm{~mm}$ corresponded to the processing parameters.

\section{REFERENCES:}

[1] Barrere, F., Mahmood, T, A., De Groot, K., Van Blitterswijk, C, A. Advanced biomaterials for skeletal tissue regeneration: Instructive and smart functions. Materials Science and Engineering. Report number: 59, (1). 2008: 38-71.

[2] Domingos, M., Dinucci, D., Cometa, S., Alderighi, M., Bártolo, P. J., Chiellini, F. Polycaprolactone scaffolds fabricated via bioextrusion for tissue engineering applications. International journal of biomaterials. 2009.

[3] Gattazzo, F., De Maria, C., Whulanza, Y., Taverni, G., Ahluwalia, A., Vozzi, G. Realisation and characterization of conductive hollow fibers for neuronal tissue engineering. Journal of Biomedical Materials Research Part B: Applied Biomaterials. 2015; 103, (5): 1107-1119.

[4] Zhao, X., Kim, J., Cezar, C. A., Huebsch, N., Lee, K., Bouhadir, K., Mooney, D. J. (2011). Active scaffolds for on-demand drug and cell delivery. Proceedings of the National Academy of Sciences, 108(1), 67-72.

[5] Gaikwad, V, V., Patil, A. B., Gaikwad, M, V. Scaffolds for drug delivery in tissue engineering. International Journal of Pharmaceutical Sciences and Nanotechnology. 2008; 11: 13-22.

[6] Potente, H., Schöppner, V. A throughput model for grooved bush extruders. International Polymer Processing. 1995; 10, (4): 289-295.

[7] Anderson, J. D., Wendt, J. Computational fluid dynamics (Vol. 206). New York: McGraw-Hill. 1995. 